\title{
Penerapan Game Development Life Cycle Untuk Video Game Dengan Model Role Playing Game
}

\author{
Mustofa $^{1}$, Jordy Lasmana Putra ${ }^{2}$, Chandra Kesuma ${ }^{3}$ \\ ${ }^{1,3}$ Program Studi Teknologi Komputer, Fakultas Teknik dan Informatika Universitas Bina Sarana Informatika, \\ Jl. Kramat Raya No.98, Jakarta Pusat, DKI Jakarta 10450, Indonesia \\ ${ }^{2}$ Program Studi Teknik Informatika, Sekolah Tinggi Manajemen Informatika dan Komputer Nusa Mandiri \\ Jl. Jatiwaringin No. 2, Cipinang Melayu, Makasar, Jakarta Timur - 13620, Indonesia \\ e-mail: ${ }^{1}$ mustofa.muo@bsi.ac.id ,2jordy.jlp@nusamandiri.ac.id, ${ }^{3}$ chandra.cka@bsi.ac.id
}

Artikel Info : Diterima : 16-12-2020| Direvisi : 28-12-2020| Disetujui : 04-01-2021

\begin{abstract}
Abstrak - Perkembangan teknologi dan informasi mendorong percepatan dunia yang sangat dinamis. Dengan adanya dorongan tersebut, teknologi komputer yang dahulu diciptakan sebagai alat bantu pekerjaan manusia saja, kini telah berkembang menjadi sarana permainan, hiburan, komunikasi dan lain sebagainya. Pada bidang hiburan salah satu buah teknologi yang banyak digemari adalah industri video game. Namun informasi dan pengetahuan mengenai pengembangan video game belum begitu diminati di Indonesia terutama tentang life Cycle pada proses pengembangan video game. Terlebih lagi video game juga memiliki berbagai macam genre dan role-play yang berbeda-beda. Sehingga tidak semua model Game Development Life Cycle (GDLC) cocok dengan kategori game tertentu, terutama yang bergenre RPG (Roled Playing Game) yang memiliki role-play yang unik. Sehingga sangat diperlukan pengujian model yang sesuai. Penelitian ini bertujuan untuk menguji apakah Game Develompment Life Cylce yang diajukan oleh Rido Ramadan dan Yani Widyani dapat digunakan pada pengembangan video game jenis RPG (Roled Playing Game). Hasilnya menunjukan pengembangan video game dengan menggunakan Game Development Life Cycle (GDLC) yang diajukan oleh Rido Ramadan dan Yani Widyani ini video game dapat berjalan dengan baik.
\end{abstract}

Kata Kunci : Video Game, GDLC, Development

Abstracts - The development of technology and information drives the acceleration of a very dynamic world. With this discovery, computer technology, which was created as a tool for human work, has now developed into a means of games, entertainment, communication and so on. In the entertainment sector, one of the most popular pieces of technology is the video game industry. However, information and knowledge regarding video game development is not very popular in Indonesia, especially about the Life Cycle in the video game development process. In addition, video games have a wide variety of genres and different role-plays. So that not all Game Development Life Cycle (GDLC) models fit into certain game categories, especially the RPG (Roled Playing Game) genre which has unique role-playing. So it is necessary to have a suitable testing model. This study aims to test whether the Life Cylce Development Game proposed by Rido Ramadan and Yani Widyani can be used in the development of RPG (Roled Playing Game) video games. The results show that video game development using the Game Development Life Cycle (GDLC) proposed by Rido Ramadan and Yani Widyani, this video game can run well.

Keywords : Video Game, GDLC, Development

\section{PENDAHULUAN}

Perkembangan teknologi semakin cepat bergerak maju untuk membuat inovasi baru dalam berbagai segi kehidupan. Ditandai dengan adanya perkembangan teknologi di berbagai bidang. Bukan hanya teknologi yang digunakan untuk membantu meringankan pekerjaan manusia, namun juga teknologi yang digunakan untuk hiburan juga semakin berkembang pesat, salah satunya adalah video game. Pada saat ini, video game adalah permainan sebagai media hiburan yang semakin lama makin berkembang (Indahtiningrum, 2013). Video game merupakan hal yang dominan dalam 20 tahun terakhir karena video game saat ini lebih canggih dan makin beragam (Padilla-

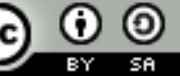

This work is licensed under a Creative Commons Attribution-ShareAlike 4.0 International License. 
Walker et al., 2010). Perkembangan video game ini dibuktikan dengan pendapatan video game secara global yang terus melonjak dan diperkirakan akan terus meningkat sampai tahun 2021 (Newzoo, 2018). Lonjakan ini terjadi di semua kategori video game yang dikembangkan baik yang berbasis console, desktop, maupun mobile. Selain itu video game juga salah satu hiburan yang diminati oleh berbagai kalangan masyarakat. Dari anak-anak hingga yang sudah dewasa juga memainkan video game baik sebagai hiburan semata maupun yang memaiknanya sebagai seorang professional (Juariyah, 2018). Tidak hanya sebagai pemain namun ketenaran video game pun ramai dijadikan tontonan. Dari sekian banyak jenis live-streaming di internet, video game streaming berada di posisi teratas (Tassi, 2013). Hal ini dapat terjadi karena video game sekarang mampu menjangkau khalayak yang lebih luas berkat tersedianya banyak pilihan video game yang dapat diakses melalui perangkat ponsel pintar dan tablet(Ottelin, 2015).

Dalam pengembangan video game sangat diperlukan alur pengembangan seperti pengembangan sebuah sistem atau yang seringkali disebut dengan istilah System Developmet Life Cycle (SDLC). Pengembangan video game yang pada awalnya menggunakan SDLC, saat ini telah mulai berubah mengikuti perkembangan teknologi. Video game merupakan sebuah sistem yang di dalamnya tidak murni hanya pengembangan sistem, dan juga tidak murni mengenai seni, kreatifitas dan imajinasi, melainkan kombinasi dari hal-hal tersebut (Ramadan \& Widyani, 2013). Dengan demikian pengembangan sebuah video game sangat memerlukan adanya panduan khusus yang lebih spesifik pada kebutuhan video game. Sehingga munculah istilah Game Development Life Cycle (GDLC) yang merupakan penyesuain SDLC agar lebih mudah diterapkan dalam pengembangan video game. Dalam Pengembangan video game saat ini terdapat beberapa model GDLC yang populer, beberapa diantaranya yang dirancang oleh oleh Arnold Hendrick, Blitz Games Studios, Penny de Byl, Doppler Interactive dan Heather Chandler. Setiap model GDLC yang dikembangkan akan memiliki karakteristik yang cukup berbeda sesuai dengan kondisi dan kebutuhan dari pengembang video game.

Di lain sisi video game juga memiliki macam-macam model permainan seperti Role-playing game (RPG), Shooters, Puzzle, Strategi, Simulasi, Adventure dan masih banyak lagi. Sedangkan untuk sub-kategori dipergunakan untuk membagi kategori utama pada video game secara lebih spesifik (Thorn, 2014). Model permainan atau genre(aliran) adalah sebuah kategori dari game berdasarkan tantangan dalam permainan, terlepas dari latar sebuah video game (Adams, 2010)

Mengkaji dari penelitian yang pernah dilakukan sebelumnya oleh Adiwikarta (Adiwikarta \& Dirgantara, 2017) yang telah mengembangkan video game beraliran endless game dengan menggunakan model GDLC miliknya. Model GDLC yang ditawarkan tersebut kurang tepat apabila diterapkan dalam pengembangan video game yang beraliran Role-playing game (RPG) disebabkan video game beraliran Role-playing game (RPG) memiliki storyline, quest dan aturan yang lebih kompleks. Video game dengan aliran RPG membutuhkan GDLC yang mempunyai tahap-tahap khusus yang dapat terapkan oleh pengembang agar bisa fokus pada desain storyline, quest, rule dan pada unsur lainya yang terdapat pada video game RPG. Tujuan dari penelitian ini adalah untuk mengembangkan video game beraliran RPG yang dengan menerapkan GDLC yang dikembangkan oleh Rido Ramadan dan Yani Widyani, serta untuk menguji GDLC yang dikembangkan Rido Ramadan dan Yani Widyani dapat digunakan dengan baik dalam pembuatan video game ber-genre RPG.

\section{METODE PENELITIAN}

Penelitian ini menggunakan metode yang Game Development Life Cycle yang dikembangkan oleh Rido Ramadan dan Yani Widyani (Ramadan \& Widyani, 2013) yang disusun dalam enam tahapan. Maing-masing tahapan saling terkait antara satu dengan yang lainnya. Ilutrasi GDLC ini dapat dilihat pada Gambar 1.

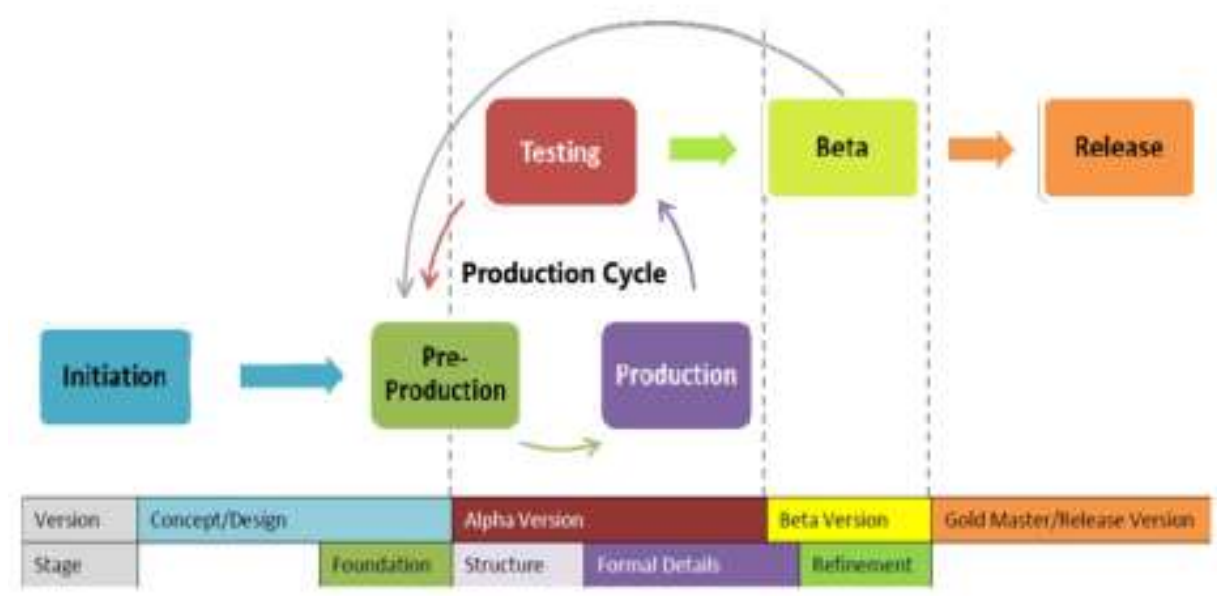


Sumber: (Ramadan \& Widyani, 2013)

\section{Initation}

Gambar 1. GDLC

Langkah pertama yang harus dilakukan dalam membuat sebuah video game adalah dengan membuat konsep kasar game seperti apa yang akan dibuat. Keluaran dari langkah pertama ini adalah konsep permainan dan deskripsi permainan yang dijabarkan dengan sederhana.

\section{Pre-Production}

Pre-Production atau Pra-produksi adalah salah satu fase utama dan terpenting dalam siklus produksi. Praproduksi melibatkan pembuatan dan revisi desain video game dan pembuatan prototipe video game. Fokus pada desain video game menentukan genre game, gameplay, mekanik, alur cerita, karakter, tantangan, faktor kesenangan, aspek teknis, dan dokumentasi elemennya dalam dokumen desain game. Setelah dokumen desain game dibuat, bentuk prototipe dibuat untuk menilai desain game dan keseluruhan idenya. Pada iterasi pertama siklus produksi, yang dibuat prototipe adalah fondasi dan struktur, sedangkan di iterasi berikutnya, prototipe terkait yang akan disempurnakan adalah detail dan perbaikan formal.

Dasar dari prototipe pertama, terkait dengan kriteria kualitas kesenangan. Dasar ini digunakan untuk menunjukkan mockup gameplay inti dan kemampuan game. Kriteria kualitas kesenangan diuji melalui kuesioner atau diskusi. Struktur dalam perbaikan dasar, akan terkait dengan kriteria kualitas kesenangan dan fungsional pad video game. Ini merupakan ciri utama dari struktur yang dapat menunjukkan baik itu gameplay inti dari game dan mekanika seperti aritmatika, logika, dan aturan permainan. Kuisioner dan diskusi digunakan untuk menguji kriteria kualitas kesenangan. Kemudian kriteria kualitas fungsional diuji melalui playtesting, di mana penguji diberikan beberapa tugas dan tujuan yang ingin dicapai menurut pengujian skenario. Pra- produksi berakhir saat revisi atau perubahan desain game telah disetujui dan didokumentasikan.

\section{Production}

Produksi adalah proses inti yang membahas seputar pembuatan aset, pembuatan program, dan integrasi kedua elemen. Terkait prototipe dalam fase ini adalah detail formal dan perbaikan. Detail Formal adalah struktur yang disempurnakan dengan lebih banyak mekanik dan aset lengkap. Produksi merupakan kegiatan yang terkait dengan pembuatan dan penyempurnaan detail formal menyeimbangkan, menambahkan fitur yang baru, meningkatkan kinerja, dan memperbaiki bug (terkait dengan fungsional dan penyelesaian internal kriteria kualitas).

Penyeimbangan game berarti penyesuaian terkait dengan kesulitan game untuk membuat game tersebut memiliki kesulitan yang sesuai. Perbaikan adalah prototipe lengkap yang merupakan subjek pemolesan game. Kriteria kualitas pada tahap ini terkait permainan harus menyenangkan dan mudah diakses. Kegiatan selama penyempurnaan diarahkan untuk membuat game lebih menyenangkan, menantang, dan lebih mudah dipahami. Hanya perubahan kecil diperbolehkan dalam fase ini.

\section{Testing}

Pengujian dalam konteks ini berarti pengujian internal yang dilakukan untuk menguji fungsi operasional dan kemampuan bermain game. Metode pengujian khusus untuk setiap tahap prototipe. Pengujian Detail Formal dilakukan dengan menggunakan playtest untuk menilai fungsionalitas fitur dan kesulitan permainan (terkait dengan keseimbangan).

Metode untuk menguji kriteria kualitas fungsional melalui fitur playtesting untuk menguji kualitas lengkap secara internal bisa dilakukan melalui playtesting secara bersamaan dengan uji fungsionalitas. Saat penguji menemukan bug, celah, atau jalan buntu selama playtesting, penyebabnya dan skenario untuk mereproduksi kesalahan yang diperlukan didokumentasikan dan dianalisis. Untuk menguji keseimbangan kriteria kualitas, playtesting dengan beberapa perbedaan perbaikan digunakan untuk mengkategorikan apakah suatu perbaikan terlalu sulit, terlalu mudah, atau tidak diperlukan.

Pengujian Perbaikan berhubungan dengan kualitas kesenangan dan kriteria kualitas aksesibilitas. Dalam pengujian perbaikan, kesenangan diuji melalui tes bermain dan umpan balik langsung dari sesama pengembang, baik itu membosankan, membuat frustrasi, menantang, dll. Aksesibilitas dapat diuji melalui mengamati perilaku penguji. Jika penguji merasa kesulitan untuk memainkan dan memahami permainan, itu berarti bahwa game belum cukup mudah diakses. Output dari pengujian adalah laporan bug, permintaan perubahan, dan keputusan pembangunan. Hasilnya akan menentukan apakah sudah waktunya untuk maju ke fase berikutnya (Beta) atau mengulangi siklus produksi.

\section{Beta}

Beta adalah fase untuk melakukan pengujian oleh pihak ketiga atau eksternal yang disebut pengujian 
beta atau beta testing. Pengujian beta masih menggunakan metode pengujian yang sama dengan metode pengujian sebelumnya, karena prototipe terkait dalam pengujian beta merupakan detail formal dan penyempurnaan. Metode pemilihan penguji hadir dalam dua jenis: beta tertutup dan beta terbuka. Beta tertutup hanya mengizinkan individu yang diundang untuk menjadi peserta, sedangkan beta terbuka memungkinkan siapa saja yang mendaftar menjadi peserta. Kriteria kualitas dalam versi beta terkait erat dengan tahap prototipe saat ini.

Dalam pengujian detail formal, penguji diminta untuk menemukan bug (terkait dengan kriteria kualitas fungsional dan lengkap secara internal). Dalam uji perbaikan, penguji diberikan kebebasan lebih untuk menikmati permainan, karena tujuannya lebih diarahkan untuk mendapatkan umpan balik (terkait kriteria kualitas kesenangan dan aksesibilitas). Keluaran dari pengujian beta adalah laporan bug dan masukan pengguna. Sesi beta ditutup terutama karena 2 alasan, baik istilah beta berakhir atau jumlah penguji beta yang ditentukan telah memberikan laporan pengujian mereka. Dari sini, dapat mengarah ke siklus produksi lagi untuk menyempurnakan produk atau terus merilis game jika hasilnya memuaskan.

\section{Release}

Ini adalah fase dimana pengembangan video game telah mencapai tahap akhir dan siap dirilis ke publik. Rilis melibatkan peluncuran produk, dokumentasi proyek, berbagi pengetahuan, post-mortem, dan perencanaan untuk pemeliharaan dan perluasan game.

\section{HASIL DAN PEMBAHASAN}

Sesuai dengan metode Game Development Life Cycle hasil dari penelitian yang dilakukan sebelumnya oleh Ramadan dan Yani Widyani maka pembahasan dalam penelitian ini akan disusun sesuai metode tersebut.

\section{Initation}

Tahap pertama dilakukan adalah membuat konsep kasar game yang akan dibuat. Langkah pertama ini menyusun konsep permainan berupa sebuah video game dengan basis dua dimensi. Selain itu video game yang dibuat juga harus memiliki unsur budaya khas Indonesia. Nama dari video game ini adalah Nusantara Legacy.

\section{Pre-Production}

Pada tahap ini melanjutkan penjabaran lebih luas daripada tahap sebelumnya dengan melakukan pembuatan prototipe video game. Pada tahap ini pembahasan lebih fokus pada desain video game dengan lebih rinci. Seperti menentukan genre game adalah Role Playing Model (RPG), kemudian mementukan gameplay yang diterapkan adalah action-fighting game, serta menyusun bagaimana interaksi pemain dan video game dengan menyusun mekanika permanainan.

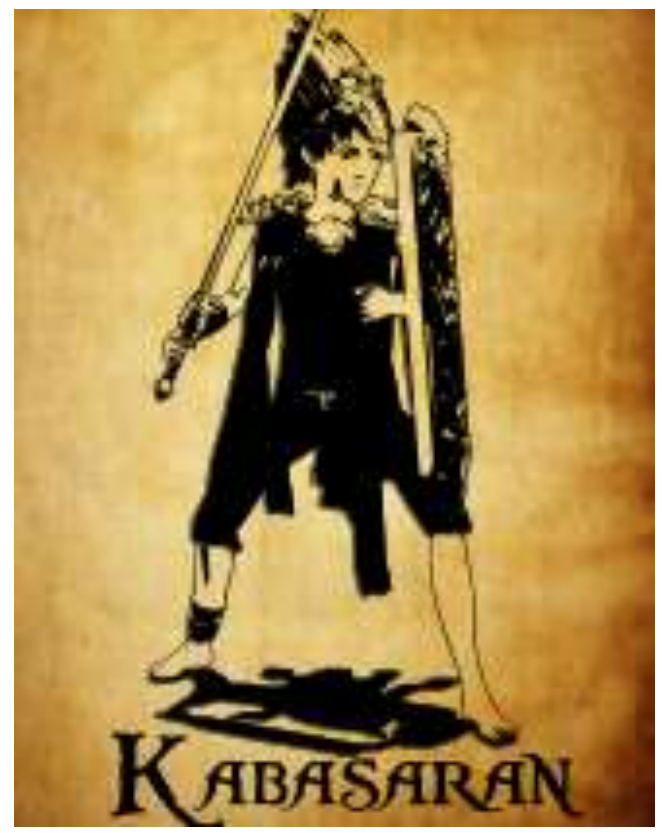

Sumber: (Mustofa dkk, 2021) 


\section{Gambar 2. Desain kasar karakter}

Pada tahap ini juga dituliskan alur cerita dalam bentuk storyboard, pembuatan karakter (lihat gambar 2) dan desain karakter kasar yang disesuaikan dengan alur cerita yang dirumuskan pada storyboard. Pada tahap ini juga dirancang tantangan-tantangan yang akan dihadapi oleh pemain dalam permainan yang harus mempertimbangkan faktor kesenangan serta aspek teknis yang harus seimbang agar video game tidak hanya dapat dijalankan, namun juga menyenangkan untuk dimainkan. Juga dirancang fitur-fitur yang terdapat pada video game. Salah satunya adalah fitur knowledge dictionary seperti yang ditunjukan pada gambar 3 .

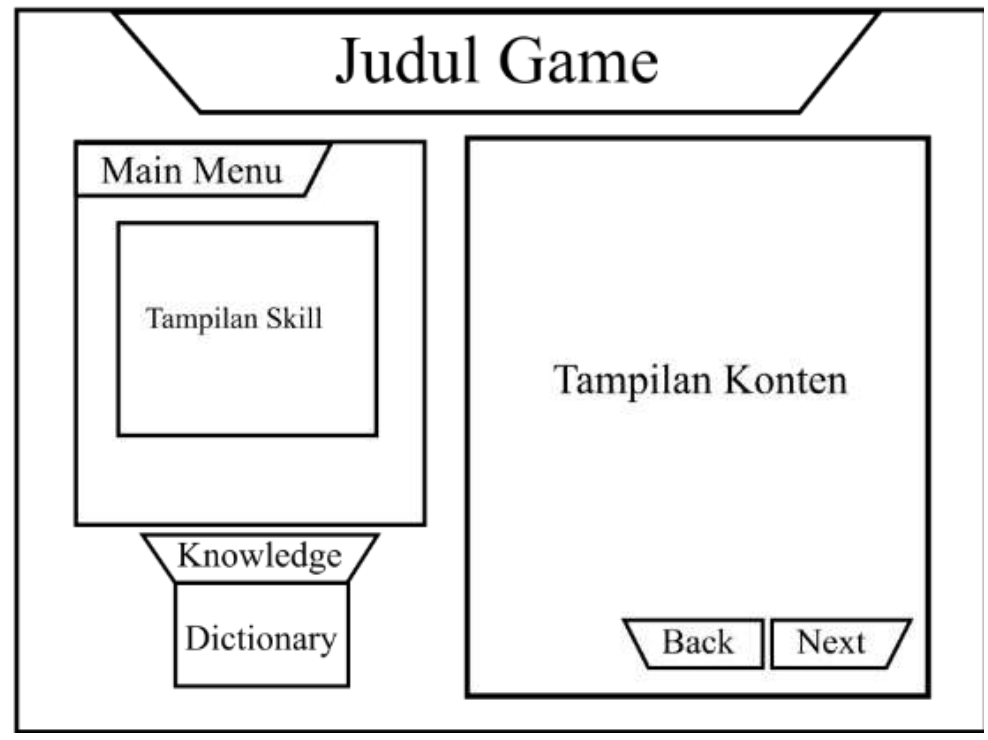

Sumber: (Mustofa dkk, 2021)

Gambar 3. Desain fitur pada game

Semua pembahasan pada tahap ini didokumentasikan dalam dokumen desain game. Setelah dokumen desain game dibuat, bentuk prototipe dibuat untuk menilai desain game dan keseluruhan idenya. Dasar dari prototipe pertama, terkait dengan kriteria kualitas kesenangan. Dasar ini digunakan untuk menunjukkan mockup gameplay inti dan kemampuan game nantinya. Sepetri yang ditunjukan pada gambar 4. Yang menampilkan dokumentasi dari alur fitur dalam video game.

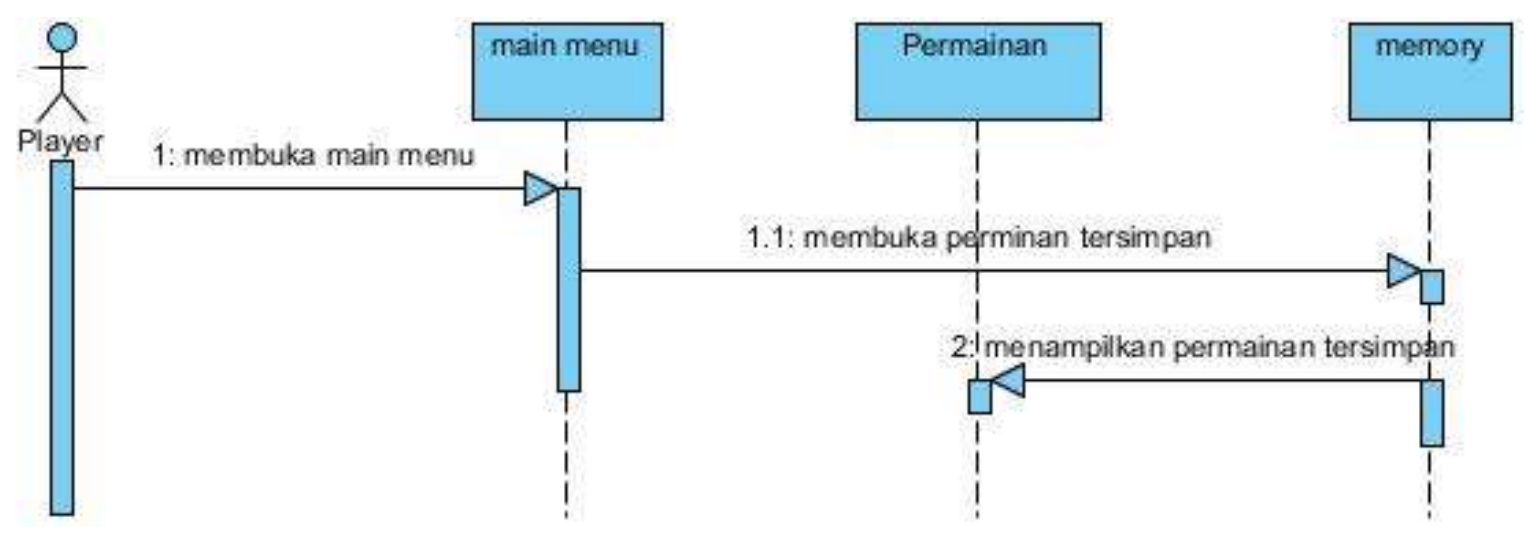

Sumber: (Mustofa dkk, 2021)

Gambar 4. alur fitur load pada game

Kriteria kualitas kesenangan diuji melalui diskusi oleh para pengembang. Diskusi juga digunakan untuk menguji kriteria kualitas kesenangan pada permainan ini. Kemudian kriteria kualitas fungsional diuji melalui playtesting, di mana penguji diberikan beberapa tugas dan tujuan yang ingin dicapai menurut pengujian skenario. Pra- produksi berakhir saat revisi atau perubahan desain game telah disetujui dan didokumentasikan. 


\section{Production}

Pada tahap poduksi ini, mockup dan desain yang sudah didokumentasikan pada tahap pra-produksi dibuat dan disempurnakan dengan detail. Pada tahap produksi ini saling terkait antara pembuatan asset dan pengukuran kinerja yang direncanakan sehingga sangat diperlukan perhitungan beban aset dan performa. Pada gambar 4 ditunjukan bagaiamana hasil produksi dari mockup yang dibuat pada tahap pra-produksi.

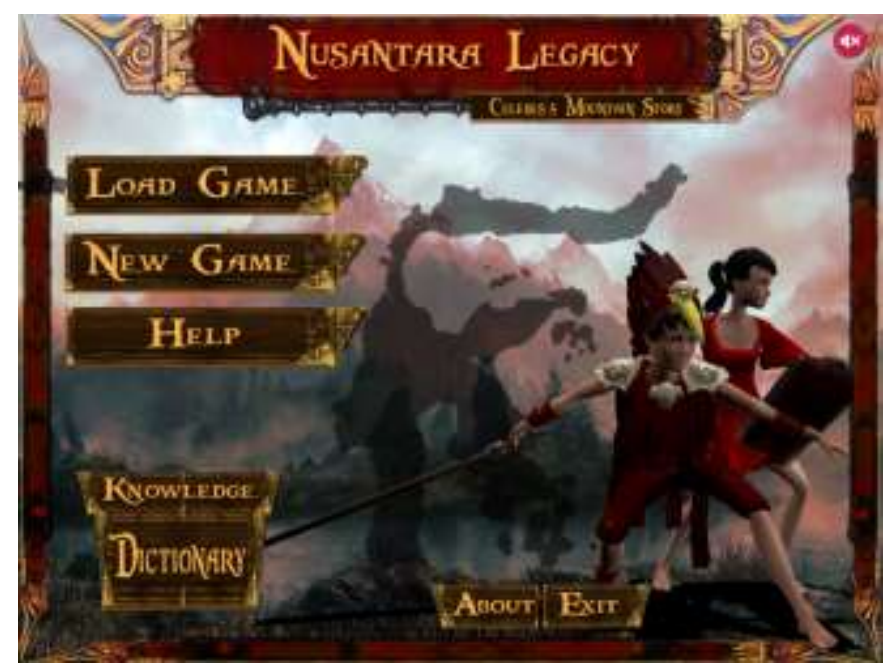

Sumber: (Mustofa dkk, 2021)

Gambar 4. alur fitur load pada game

Penyeimbangan game juga diukur dengan kesulitan game untuk membuat game tersebut memiliki kesulitan yang sesuai. Kriteria kualitas pada tahap ini terkait permainan harus menyenangkan dan mudah diakses. Sehingga penyediaan fitur-fitur yang sebelumnya mungkin belum terfikirkan dapat ditambahkan pada tahap ini. Kegiatan selama penyempurnaan diarahkan untuk membuat game lebih menyenangkan, menantang, dan lebih mudah dipahami. Namun hanya perubahan kecil saja yang diperbolehkan dalam fase ini.

\section{Testing}

Pengujian internal dilakukan untuk menguji fungsi operasional dan kemampuan bermain game. Metode pengujian dilakunak denga metode blackbox testing untuk memastikann permainan dapat dijalankan sesuai dengan rencana pengembangan video game. Selain itu juga dilakukukan pengujian dengan metode untuk menguji kriteria kualitas fungsional melalui fitur playtesting untuk menguji kualitas lengkap secara internal bisa dilakukan melalui playtesting secara bersamaan dengan uji fungsionalitas. Saat penguji menemukan bug, celah, atau jalan buntu selama playtesting, penyebabnya dan skenario untuk mereproduksi kesalahan yang diperlukan didokumentasikan dan dianalisis. Untuk menguji keseimbangan juga dilakukan, playtesting dengan beberapa perbedaan perbaikan digunakan untuk mengkategorikan apakah suatu perbaikan terlalu sulit, terlalu mudah, atau tidak diperlukan.

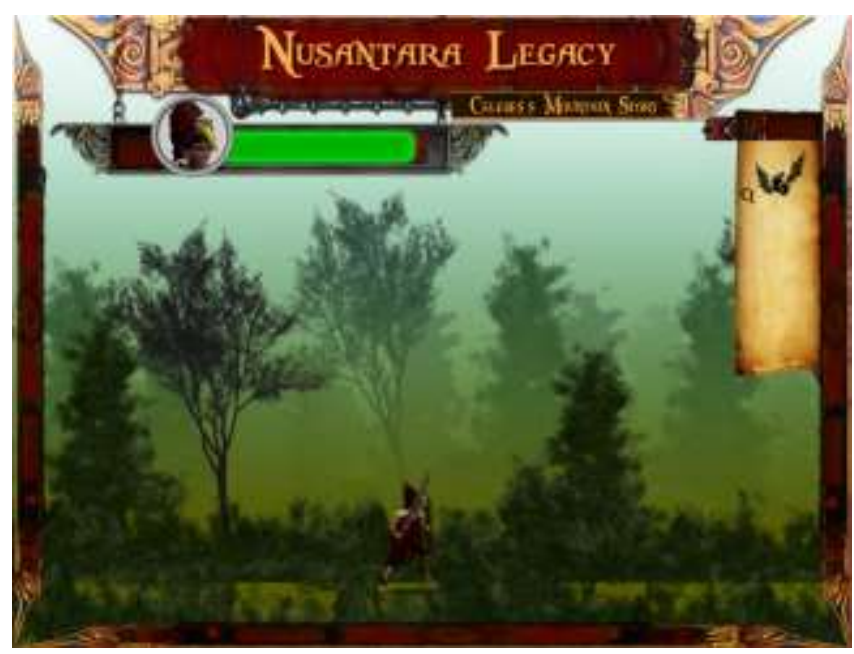


Sumber: (Mustofa dkk, 2021)

Gambar 5. Testing internal

Dalam pengujiankembali saat dilakukan perbaikan diuji melalui tes bermain dan umpan balik langsung dari sesama pengembang akan dikategorikan membosankan, membuat frustrasi, menantang, dll. Aksesibilitas dapat diuji melalui mengamati perilaku penguji. Jika penguji merasa kesulitan untuk memainkan dan memahami permainan, itu berarti bahwa game belum cukup mudah diakses. Maka akan dilakukan perbaikan pada tahap reproduksi.

\section{Beta}

Pada tahap ini dilakukan pengujian oleh pihak eksternal. Pengujian beta masih menggunakan metode pengujian yang sama dengan metode pengujian sebelumnya. Pengujian beta dilakukan dengan metode beta tertutup yang hanya mengizinkan individu yang diundang untuk menjadi peserta, Penguji diberikan kebebasan lebih untuk menikmati permainan, karena tujuannya lebih diarahkan untuk mendapatkan umpan balik sehingga ditemukan laporan tentang adanya bug

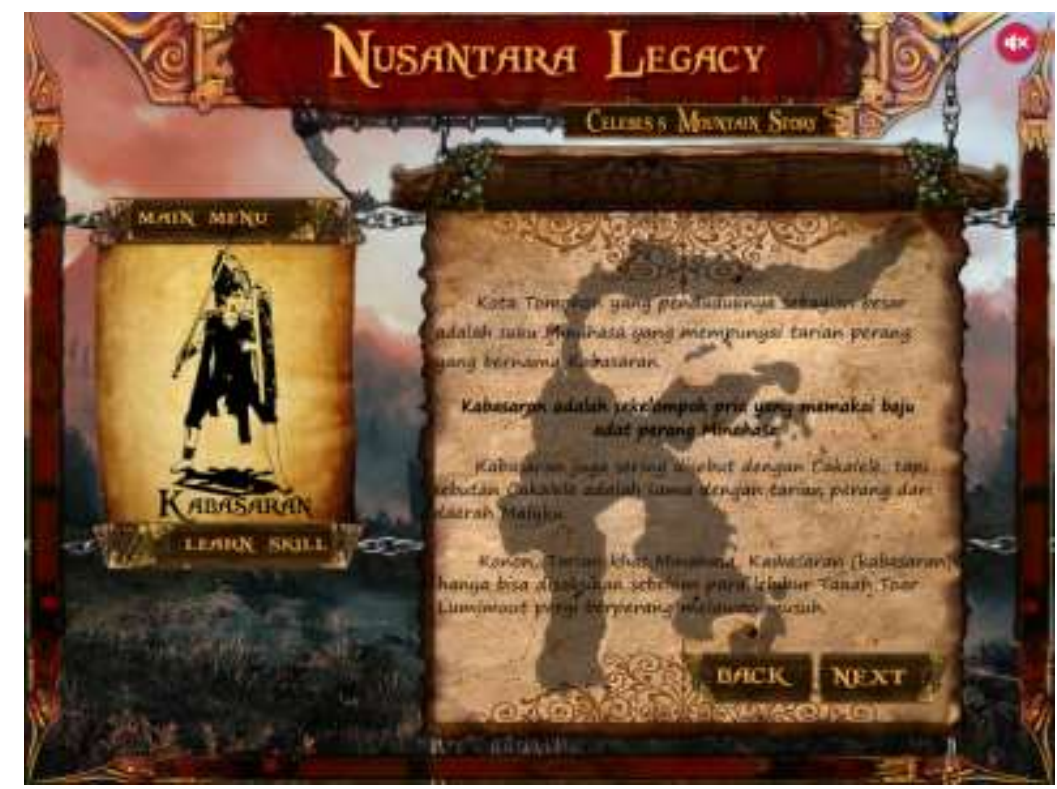

\section{Release}

Tahapan ini pengembangan video game telah mencapai tahap akhir dan siap dirilis ke publik. Rilis melibatkan peluncuran produk, dokumentasi proyek, dan perencanaan untuk pemeliharaan dan perluasan game.

Sumber: (Mustofa dkk, 2021)

Gambar 6. Tampilan game

\section{KESIMPULAN}

Penelitian ini telah mencoba untuk menerapkan GDLC (Game Development Life Cycle) yang disusun Rido Ramadan dan Yani Widyani dengan mengembangkan video game berbasis dua dimensi. Hasilnya adalah penerapan GDLC model ini dapat diterapakan dan berjalan dengan sangat baik pada video game beraliran RPG (Roled Playing Game) tanpa kendala yang berarti. GDLC model ini ini mendeskripsikan tahapan-tahapan pengembangan yang lengkap serta memberikan keleluasaan bagi pengembang dalam mengekplorasi bagian dari video game beraliran RPG. Terutama adalah pembgian tahapan pra-produksi yang memberikan kesempatan untuk mematangkan story board yang merupakan ciri khas dari video game RPG Untuk peneltian kedepan dapat dilakukan perbandingan antara beberapa GDLC terhadap beberapa genre video game untuk menentukan GDLC yang paling tepat untuk digunakan pada pengembangan video game dengan genre tertentu. 


\section{REFERENSI}

Adams, E. (2010). Fundamentals of Game Design. In Choice Reviews Online (2nd ed.). New Rider. https://doi.org/10.5860/choice.47-4462

Adiwikarta, R., \& Dirgantara, H. B. (2017). Pengembangan Permainan Video Endless Running Berbasis Android Menggunakan Framework Game Development Life Cycle Rendy. Jurnal Sains Dan Teknologi, 4, 142-148.

Indahtiningrum, F. (2013). Hubungan antara kecanduan video game dengan stres pada mahasiswa universitas surabaya fitriana indahtiningrum. Jurnal Ilmiah Universitas Surabaya, 2(1), 1-17.

Juariyah, J. (2018). Pengalaman Bermain Video Games Sebagai Kegiatan Leisure Class Middle Lower Remaja Kampung Tanoker. Mediakom, 1(2), 155-175. https://doi.org/10.32528/mdk.v1i2.1575

Newzoo. (2018). Newzoo 2018 Global Mobile Market Report Free.

Ottelin, T. (2015). Twitch and professional gaming: Playing video games as a career? Degree Programme in Music and Media Management Business and Services Management. https://www.theseus.fi/bitstream/handle/10024/96979/Opinnaytetyo.pdf;sequence=1

Padilla-Walker, L. M., Nelson, L. J., Carroll, J. S., \& Jensen, A. C. (2010). More than a just a game: Video game and internet use during emerging adulthood. Journal of Youth and Adolescence, 39(2), 103-113. https://doi.org/10.1007/s10964-008-9390-8

Ramadan, R., \& Widyani, Y. (2013). Game development life cycle guidelines. 2013 International Conference on Advanced Computer Science and Information Systems, ICACSIS 2013, September 2013, 95-100. https://doi.org/10.1109/ICACSIS.2013.6761558

Tassi, P. (2013). Talking livestreams, esports and the future of entertainment with twitch. Forbes.Com. https://www.forbes.com/sites/insertcoin/2013/02/05/talkinglivestreams-\%0Aesports-and-the-future-ofentertainment-with-twitch-tv/

Thorn, A. (2014). Document retrieved from: Gale Catalog Grade Level Range: College Freshman - College Senior About Meet the Author Author Bio Alan Thorn. Cengage Course Technology. 